\title{
Kahramanmaraş'tan Toplanan Prunus divaricata subsp. divaricata Ledeb. Meyvelerinin Biyokimyasal Özellikleri ve Antimikrobiyal Aktivitelerinin Belirlenmesi
}

\author{
Nazan ÇÖMLEKCIOOGLUU ${ }^{I^{*}}$ (D) Yusuf Ziya KOCABAŞ ${ }^{2}$ (D) Ashabil AYGAN ${ }^{3}$ (1) \\ ${ }^{1,3}$ Kahramanmaraş Sütçü İmam Üniversitesi, Fen-Edebiyat Fakültesi, \\ Biyoloji Bölümü, Kahramanmaraş/TURKEY \\ ${ }^{2}$ Kahramanmaraş Sütçü İmam Üniversitesi, Türkoğlu Meslek Yüksek Okulu, \\ Tıbbi-Aromatik Bitkiler Bölümü, Kahramanmaraş/TURKEY \\ ${ }^{1}$ https://orcid.org/0000-0001-7729-5271 ${ }^{2}$ https://orcid.org/0000-0003-2831-8910 \\ ${ }^{3}$ https://orcid.org/0000-0003-4936-9872 \\ * Corresponding author (Sorumlu yazar): noktem80@gmail.com \\ Received (Gelis tarihi): 26.08.2019 Accepted (Kabul tarihi): 14.10.2019
}

\begin{abstract}
ÖZ: Prunus divaricata subsp. divaricata Ledeb. (yonuz eriği), tıbbi amaçlı kullanımının yanı sıra, yöre halkı tarafindan gıda olarak da tüketilen bir türdür. Ekonomik potansiyeli olmasina rağmen, yabani $\boldsymbol{P}$. divaricata subsp. divaricata kültüre alınmamış ve meyve tüketimi yaygınlaşmamıştır. Bu çalışmada, Kahramanmaraş'ta Ahırdağl ve Nurhak lokasyonlarından toplanan P. divaricata subsp. divaricata meyve örneklerden iki farkl ekstraktörle (soksalet ve ultrasonik banyo) elde edilen ekstraktların, toplam fenolik ve flavonoid içerikleri ile antioksidan, antimikrobiyal aktiviteleri ve ayrıca GCMS analizi ile analiz edildi ve 25 farklı yağ asidi belirlenmiştir. Ahırdağ lokasyonundan toplanan P. divaricata subsp. divaricata meyve ekstraktlarının başlıca yağ asidi bileşenlerini cis-11,14,17- eikosatrienoik asit (\%31,20) ve oleik asit (\%25,41); Nurhak lokasyonundaki bitkilerde ise oleik asit $(\% 49,77)$ ve palmitik asit $(\% 23,054)$ oluşturmaktadır. Ekstraktların biyoaktif içeriklerinin belirlenmesinde ultrasonik banyonun soksalete göre daha etkili olduğu görülmüsstür. Ahırdăğ ve Nurhak lokasyonundaki örneklerin USB metoduna göre sirasiyla toplam fenolik madde içeriği 62,50 ve 37,40 $\mathrm{mg} \mathrm{g}^{-1}$, toplam flavonoid miktarl 2,96 ve $1,81 \mathrm{mg} \mathrm{g}^{-1}$, FRAP değeri 31,05. ve 20,82 $\mathrm{g} \mathrm{g} \mathrm{g}^{-1}$ ve DPPH değeri 1,47 ve 1,65 $\mathrm{mg} \mathrm{g}^{-1}$ olarak bulunmuştur. Antimikrobiyal aktivite deneyi sonucunda, $\boldsymbol{P}$. divaricata subsp. divaricata meyve ekstraktları çalışılan 10 mikroorganizmanın tamamının (8 bakteri ve 2 mantar) gelișimini durdurmuştur. Ancak bakteriler üzerindeki inhibisyon etkisi funguslardan daha yüksek bulunmuștur.
\end{abstract}

Anahtar Kelimeler: Antimikrobiyal aktivite, antioksidan aktivite, fenol, flavonoid, yă̆ asidi, Prunus divaricata subsp. divaricata Ledeb.

\section{Determination of Biochemical Composition and Antimicrobial Activities of Prunus divaricata subsp. divaricata Ledeb. Fruits Collected from Kahramanmaraş}

ABSTRACT: Prunus divaricata subsp. divaricata is a plant that is believed to have medicinal benefits and is used for this purpose as well as consumed by the local people as food. Despite its economic potential wild P. divaricata subsp. divaricata has still not domesticated and the fruits consumption has not became prevalent. In this study, total phenolic and flavonoid content, antioxidant and antimicrobial activities of extracts obtained from two different extractors (soxhlete and ultrasonic bath) from P. divaricata subsp. divaricata fruits collected from two different locations (Ahırdağı and Nurhak) in Kahramanmaraş were investigated. In addition, fatty acids were analyzed by GC-MS analysis and 25 different fatty acids were determined. The main fatty acid components of $\boldsymbol{P}$. divaricata subsp. divaricata fruit extracts collected from the Ahirdağ location include cis-11,14,17eicosatrienoic acid (31.20\%) and oleic acid (25.41\%); in plants from Nurhak location, oleic acid (49.77\%) and palmitic acid (23.05\%). The ultrasonic bath was found to be more effective in detecting the bioactive contents of the extracts than the soxhlete. Total phenolic content of plant extracts (USB) in Ahirdağl and Nurhak locations were 62.50 and $37.40 \mathrm{mg}$ g-1, total flavonoid amount was 2.96 and $1.81 \mathrm{mg} \mathrm{g}^{-1}$, FRAP value was 31.05 and $20.82 \mu \mathrm{g} \mathrm{g}^{-1}$ and DPPH were 1.47 and $1.65 \mathrm{mg} \mathrm{g}^{-1}$. Antimicrobial activity experiment carried with a total of 10 microorganisms (eight bacteria and two yeasts) showed that $\boldsymbol{P}$. divaricata subsp. divaricata fruit extracts inhibited all of the microorganisms growth tested. However, inhibition effect on bacteria was higher than fungi.

Keywords: Antimicrobial activity, antioxidant activity, phenol, flavonoid, fatty acid, Prunus divaricata subsp. divaricata Ledeb. 


\section{GíRIŞ}

Bitkilerin çoğunluğu, özellikle oksidatif stres ile ilişkili hastalıklar olmak üzere çeşitli patolojilerin tedavisinde etkili olduğu bilinen biyoaktif bileşikler içerir (Mattioli ve ark., 2018). Birçok meyve ve sebzenin koyu mor, mavi ve kırmızı renklerinden sorumlu olan antosiyanin flavonoidleri ve çeşitli fenolik bileşikler yüksek antioksidan aktiviteleri nedeniyle son zamanlarda araștırma odağı olan bir biyoaktif bileşik sınıfıdır. (Blackhall ve ark., 2018). Biyoaktif besleyici moleküller (besinler, vitaminler, mineraller, lifler) ve ayrica fitokimyasallara (fenolik bileşikler, flavonoidler, biyoaktif peptitler) sahip olmasindan dolayı, meyve ve sebzeler beslenme düzeni ve sağliklı yaşamda önemli bir rol oynamaktadır (SeptembreMalaterre ve ark., 2018). Bu nedenle, artan dünya nüfusu ve değişen beslenme alışkanlıkları dolayısıyla bu ürünlere olan talep artış göstermektedir (Schieber ve ark., 2001). Diğer taraftan, çok sayıda ve ulaşılabilir sentetik ilaca rağmen, bitkisel ilaçlara ilgi devam etmektedir. Dünyada yaklaşık 4 milyar insanın (dünya nüfusunun \%80'i) sağlı sorunlarını ilk etapta bitkisel ilaçlarla gidermeye çalıştıkları bildirilmiştir (Ekor, 2014). Yüksek miktarda biyoaktif bileşik içeriği nedeniyle (Mocan ve ark., 2018), günümüzde gida endüstrisinde kullanılan kimyasal koruyuculara ve antibiyotiklere alternatif olarak kullanılabilecek doğal antimikrobiyal bileşikleri içeren bitkilere yönelik çok sayıda çalıșmalar yapılmaktadır (Hintz ve ark., 2015). Bu bağlamda, enfeksiyonları önlemek amacıyla geleneksel tıpta kullanılan bitki kaynaklı antimikrobiyal ajanların özellikleri belirlenmektedir (Ramalhosa ve ark., 2011).

Türkiye coğrafi konumu, iklim ve bitki çeşitliliği, geniş yüzölçümü sayesinde tıbbi ve aromatik bitkiler açısından önemli ülkelerden biridir. $\mathrm{Bu}$ sayede bitkisel ilaç, bitki kimyasalları, gıda ve katkı maddeleri, kozmetik ve parfümeri sanayilerinde kullanılan pek çok bitkisel ürün elde edilebilmektedir. $\mathrm{Bu}$ bitkiler çoğunlukla doğadan toplanarak pazarlanmaktadır (Faydaoğlu ve Sürücüoğlu, 2011). Çoğu bitkinin çeşitli hastalıklara karşı koruyucu etkiye sahip olmasının yanı sıra sağlık için gerekli olan vitamin ve mineralleri içermesine rağmen, popüler ve geleneksel kullanımla ilgili bilgilerin çoğu, bitkilerin etkinliğini ve güvenliğini belirlemek için yeterli değildir (Teixeira ve ark.,
2019). $\mathrm{Bu}$ nedenle, birçok türün beslenme özelliklerini araştırmaya ve sağlığa yararlı etkilerini bulmaya ihtiyaç vardır. Tıbbi bitki, gıda, kozmetik ve parfümeri ve peyzaj gibi birçok alanda değerlendirilen üyeleriyle Rosaceae familyası, ülkemizdeki önemli bitki ailelerinden biridir. Rosaceae familyasının ekonomik öneme sahip olan çoğu cinsinden birisi de Prunus L.'dur. Prunus L. cinsinin türleri kuzey yarımkürede dağılmış olup türlerin çoğu yarı sert iklimlerde görülür (Dönmez ve Yıldırıml1, 2000). P. divaricata Ledeb., Prunus cinsine ait, yabani, diploid bir meyve ağacıdır (Reales ve ark., 2010). Türler, Kuzey İran'ın Hyrcanian ormanları da dahil olmak üzere, Balkan Yarımadası'ndan Anadolu ve Kafkasya'ya kadar Orta Asya'ya geniș çapta dağılmıștır. 2-4 cm çapında taze meyveler bulundukları yörede halkın diyetinin bir parçasıdır veya çiğ yenir ya da tart malzemesi, marmelat ve reçel hazırlamak için kullanılır (Wöhrmann ve ark., 2011). Literatürde tansiyon ve hiperlipidemi etkilerinin azaltılması, kanser, romatizma ve ateroskleroz gibi hastalıkların önlenmesi, diyabet, soğuk algınlığı, grip, astım, nefrit gibi hastalıklarda tıbbi etkileri bildirilmiştir (Kültür, 2007; Minaiyan ve ark., 2014). Ayn1 zamanda bir anaç olarak da kullanılmaya uygun ve kültüre alınma potansiyeli olan, çiftçilere ekonomik ve geçim avantajları sağlayabilecek ekonomik bir türdür (Wöhrmann ve ark., 2011).

$\mathrm{Bu}$ çalışmanın amacı, $P$. divaricata subsp. divaricata'dan elde edilen ekstraktlarm biyoaktif bileşen ve antioksidan aktivitesinin yanı sira antimikrobiyal aktivitesini araştırmaktır. Ayrıca ekstraktlar GC-MS yardımıyla analiz edilerek, bitki meyvelerinin yağ asidi profili incelenmiştir. $\mathrm{Bu}$ çalışma, $P$. divaricata subsp. divaricata üzerinde kapsamlı olarak yapılan ilk çalışmadır.

\section{MATERYAL ve METOT}

\section{Bitki materyali}

$\mathrm{Bu}$ çalışmada, $P$. divaricata subsp. divaricata bitkilerine ait meyve örnekleri, Ekim 2017'de Kahramanmaraş'ta Nurhak ve Ahırdağı olmak üzere iki farklı lokasyondan toplanmıştır. Nurhak ilçesi $37^{\circ} 55^{\prime} 27^{\prime}$ ' $\mathrm{N}$ ve $37^{\circ} 28^{\prime} 05^{\prime}$ ' E koordinatlarındaki doğal floradaki toplanan örneklere YZK-2198 herbaryum numarası verilmiştir. Ahırdağı ilçesi $37^{\circ} 37^{\prime} 25^{\prime \prime} \mathrm{N}$ ve $36^{\circ} 55^{\prime} 13^{\prime \prime} \mathrm{E}$ koordinatlarındaki 
doğal floradan toplanan örneklere ise, YZK-2197 herbaryum numarası verilmiştir (Şekil 1). Bitkiler Flora of Turkey'e göre teşhis edilmiş ve herbaryum numaras1 verilen örnekler KSU Herbaryumu'nda muhafazaya alınmıştır (Davis, 1965).

\section{Örnek hazırlı̆̆ı}

Doğal ortamlarındaki farklı ağaçlardan bitkinin olgunlaşmış meyveleri toplanmıştır. Laboratuar ortamına getirilen meyvelerin çekirdekleri çıkarılmış ve etli kısımlar yaklaşık iki hafta süreyle oda sıcaklığında, rutubetsiz bir ortamda kurutulmuştur. $\mathrm{Bu}$ örnekler laboratuvar blenderinde (Waring Commercial) öğütülerek toz haline getirilip, deneyde kullanılmak üzere 1 şı ve nemden korunarak cam şişelerde saklanmıştır.

\section{Ekstraksiyon metodu}

$P$. divaricata subsp. divaricata bitkisine ait ögütülmüş meyve örneklerinden polifenollerin ekstraksiyonunu sağlamak amaciyla metanol (Polarite indeksi: 6,6) çözücüsüyle aşağıda belirtilen şekillerde iki farklı ekstraksiyon metodu uygulanmıştır. Biyoaktif içeriğin ekstrakta geçirilmesinde biri geleneksel (soksalet), diğeri ise modern (Ultrasonik banyo) olan iki farklı ekstraktör kullanılarak, iki metodun kıyaslanması amaçlanmıştır. Soksalet fazla kullanılmasına rağmen, zaman alan, fazla miktarda çözücü harcanan, ekstraktın cam balonda ısıdan dolayı kömürleşmesi gibi dezavantajları olan bir metottur.

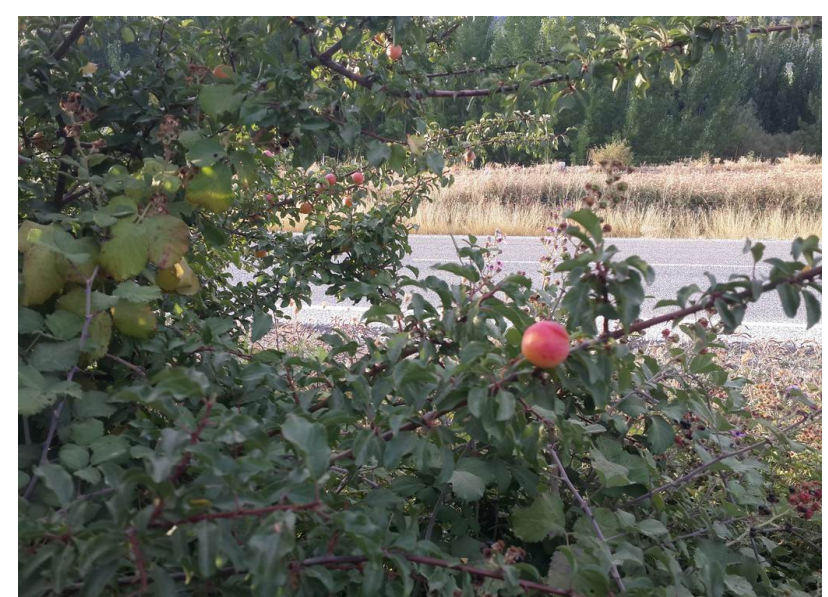

Nurhak Lokasyonu / Nurhak Location
Ultrasonik banyoda ise bu olumsuzlukların hiçbiri yaşanmamaktadır. Elde edilen bu ekstraktlarda toplam fenolik, toplam flavonoid, antioksidan aktivite tayini gerçekleştirilmiştir. Tüm deneyler üç tekerrür halinde yapılmış, ortalamalar ve standart hata çizelge olarak verilmiştir.

Soksalet metodu: $\mathrm{Bu}$ metotta, toz haldeki bitki materyalinden $10 \mathrm{~g}$ tartılmış ve üzerine $500 \mathrm{ml}$ metanol eklenip $60^{\circ} \mathrm{C}$ 'de, 18 saat süreyle Soksalet cihazında ekstraksiyon sağlanmıştır. Elde edilen ekstraktlar $48^{\circ} \mathrm{C}$ vakumlu evaporatörde çözücü uzaklaştırılarak kurutulmuştur. Kurutulmuş bitki materyali analiz yapılıncaya kadar $-20^{\circ} \mathrm{C}$ 'de muhafaza edilmiştir (Heleno ve ark., 2016).

Ultrasonik su banyosu (USB) metodu: Ekstraksiyon Miliauskas ve ark. (2004)'nın metodu modifiye edilerek yapılmıştır. 10'ar g tartılan bitki örneklerine 50'şer ml metanol eklenerek bir gece oda sıcaklığında bekletilmiş ve ardından 1 saatlik bir sürede Ultrasonik Su Banyosu'nda ekstraksiyon sağlanmıştır. Santrifüj edildikten sonra filtre kağıdı yardımıyla süzülen bitki materyali başka bir şişede toplanmış ve bitki örneği iki kez daha aynı şekilde ekstrakte edilmiştir. Ekstraktlar toplanarak 3500 rpm'de $15 \mathrm{dk}$ santrifüj edildikten sonra vakumlu rotary evaporatörde çözücü uzaklaştırılmış ve kuru ekstrakt elde edilmiştir. Kurutulmuş bitki ekstraktı analiz yapılıncaya kadar $\quad-20 \quad{ }^{\circ} \mathrm{C}$ 'de muhafaza edilmiştir.

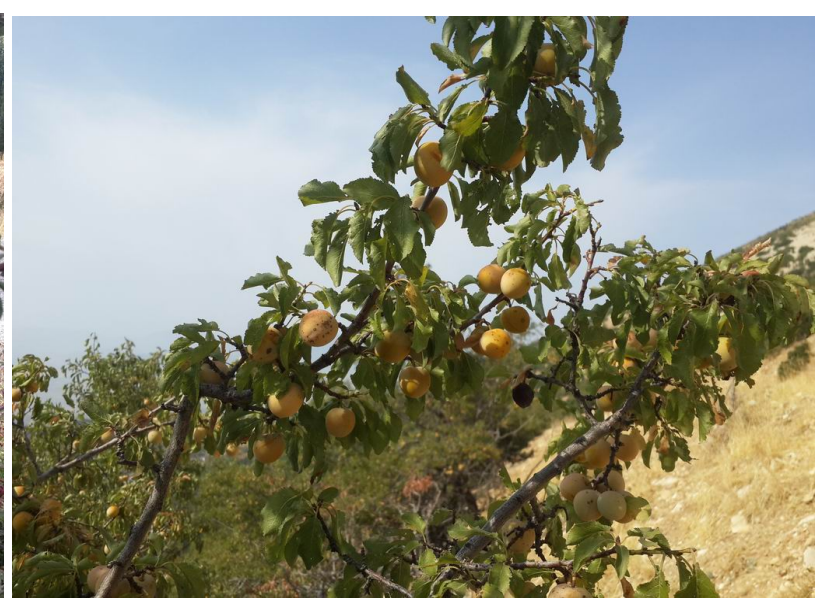

Ahırdağı Lokasyonu /Ahırdağı Location

Şekil 1. P. divaricata subsp. divaricata genotipinin Nurhak ve Ahırdağı lokasyonlarında doğal floradaki görünümü. Figure 1. View of $P$. divaricata subsp. divaricata genotype in natural flora of Nurhak and Ahırdağ locations. 
Meyve ekstraktlarının yağ içeriği ve yağ asidi kompozisyonunun belirlenmesi

Soksalet metoduyla elde edilen sabit yağ içerisindeki yağ asitlerinin analizi GC-MS ile Rivera-Rangel ve ark. (2018)'a göre yapılmıştır. GC-MS analizleri Schimadzu GC 2025 sistemi ${ }^{\circledR}$ ile gerçekleştirilmiştir. TRCN-100 $(60 \mathrm{~m} \times 0,25 \mathrm{~mm} \times 0,20 \mu \mathrm{m}$ film thickness) SE-54 fused silika kapiler kolon kullanılmıştır. Elektron enerjisi 70 eV'tur. Enjeksiyon miktarı $1 \mu \mathrm{l}$ ' dir. Örnekler $80{ }^{\circ} \mathrm{C}$ 'de 2 dakika bekletildikten sonra sicaklık dakikada $5^{\circ} \mathrm{C}$ artırılıp $140{ }^{\circ} \mathrm{C}$ 'de 2 dakika tutulmuştur. Bu işlemi takiben, dakikada $3^{\circ} \mathrm{C}^{\prime} l 1 \mathrm{k}$ bir artışla $240{ }^{\circ} \mathrm{C}$ 'da 5 dakika daha bekletilmiştir. Toplam analiz süresi 61 dakika olarak ayarlanmıştır. Enjeksiyonlar split modda (1:50) $240{ }^{\circ} \mathrm{C}$ 1sıda gerçekleştirilmiştir ve dedektör sıcaklığ $250{ }^{\circ} \mathrm{C}$ ' dir. Helyum taşıyıcı gaz olarak kullanılıp ve akış hızı $30 \mathrm{ml} \mathrm{dk}^{-1}$ ya ayarlanmıştır. Kullanılan gaz akışları $\mathrm{H}_{2}=40 \mathrm{ml} \mathrm{dk}^{-1}$ ve kuru hava $=400 \mathrm{ml} \mathrm{dk}^{-1}$ olarak belirlenmiştir.

Toplam fenolik ve flavonoid içerikleri ile antioksidan aktivitenin belirlenmesi

Toplam fenolik içerik tayini: Örneklerin toplam fenolik içeriği Folin-Ciaceltaeou Reaktif (FCR) metodu kullanılarak Obanda ve Owuor (1997)'in metodu modifiye edilerek yapılmıştır. Standart olarak gallik asit (Sigma) kullanılmıştır. Hazırlanan solüsyonlar spektrofotometrede (Perkin-Elmer Lambda EZ 150, USA) $750 \mathrm{~nm}$ 'de okunmuştur. Elde edilen absorbans değerleri gallik asit çözeltileri ile oluşturulan kalibrasyon eğrisi yardımıyla mg gallik asit eşdeğeri (GAE) $\mathrm{g}^{-1}$ kuru örnek ağırlığ cinsinden verilmiştir.

Toplam flavonoid içerik tayini: Bitki ekstraktlarındaki toplam flavonoid içeriği Chang ve ark. (2002)'a göre spektrofotometrik olarak belirlenmiştir. Standart solüsyon farklı konsantrasyonlarda $(25-200 \mu \mathrm{g} / \mathrm{mL})$ yukarıdaki metoda göre hazırlanan quercetin (Sigma) ile hesaplanmıştır. Absorbans 415 nm'de spektrofotometrede okunmuştur.
Elde edilen absorbans değerleri $\mu \mathrm{g}$ quercetin eşdeğeri/g kuru örnek ağırlığına dönüştürülmüştür.

\section{Antioksidan aktivite (AA) tayini}

DPPH (1,1-diphenyl-2-picrylhydrazyl) metodu: Antioksidan aktivite [kapasite (serbest radikallerin indirgenme kapasitesi)] Brand-Williams ve ark. (1995) tarafindan tanımlanan DPPH metodu modifiye edilerek belirlenmiştir. Her bitki ekstraktından seyreltilerek beş farklı konsantrasyonda solüsyon hazırlanmıştır. Askorbik asit pozitif kontrol olarak kullanılmıştır. Sonuçlar, DPPH serbest radikallerinin $\% 50$ 'sini indirgemek için gereken konsantrasyon değeri olan $\mathrm{IC}_{50}$ olarak gösterilmiştir.

FRAP (Ferric Reducing Antioxidant Power) metodu: Demir iyonu indirgeyici antioksidan gücün (FRAP) belirlenmesi Benzie ve Strain (1996)'a göre yapılmıştır. Bitki ekstraktlarından 50 $\mu 1,2 \mathrm{ml}$ 'lik ependorf tüplerine aktarılmış ve üzerine $600 \mu 1$ FRAP ajanı eklenmiştir. Absorbans 593 nm'de ölçülmüştür. Sonuçlar askorbik asit (100-

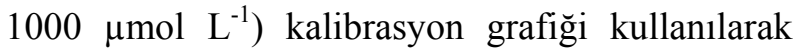
$\mu$ mol askorbik asit eşdeğeri $\mathrm{g}^{-1}$ kuru bitki ağırlığı olarak hesaplanmıştır.

\section{Antimikrobiyal aktivitenin belirlenmesi}

Meyve ekstraktlarının antimikrobiyal aktivitesi, Klinik Laboratuar Standartları Ulusal Komitesi'ne (NCCLS) göre oyuk agar difüzyon metodu ile belirlenmiştir (Anonymous, 1993). Test mikroorganizmaları olarak Escherichia coli, Klebsiella pneumonia, Bacillus subtilis ATCC 6633, Enterococcus faecalis ATCC 29212, Enterococcus faecium, Staphylococcus aureus ATCC 29213,MRSA (Metsilin Dirençli Staphylococcus aureus), Sarcina lutea ATCC 9341NA, Candida albicans, Candida parapsilosis olmak üzere klinik izolatlar ve standart suşlar kullanılmıştır. Bakteriler Mueller Hinton Agar'da $37^{\circ} \mathrm{C}$ 'de; maya suşları ise Sabouraud Dextrose Agar'da $30{ }^{\circ} \mathrm{C}$ 'de aktive olmaları için kültüre alınmıştır. DMSO (dimetil sülfoksit) içerisinde çözülen bitkisel ekstraktlar (16

$\%$ Antioksidan aktivite (kapasite): \%AA $=\left[\left(\mathrm{A}_{\text {kontrol }}-\mathrm{A}_{\text {örnek }}\right)\right] / \mathrm{A}_{\text {kontrol }} \mathrm{x} 100$ 
$\mathrm{mg} / \mathrm{ml}), 6 \mathrm{~mm}$ çapında aseptik koşullara uyularak açılan oyuklara $50 \mu \mathrm{l}$ ilave edilmiş ve 0,5 McFarland turbiditesine serum fizyolojik ile sulandırılan $\left(10^{8}\right.$ hücre $\left.\mathrm{ml}^{-1}\right)$ kültürden $100 \mu \mathrm{l}$ bakteri aşılanan petri kutuları $37{ }^{\circ} \mathrm{C}$ 'de 24 saat, $\left(2.1 \times 10^{3}\right.$ hücre $\left.\mathrm{ml}^{-1}\right)$ maya aşılanan petri kutuları da $30^{\circ} \mathrm{C}^{\prime}$ de $24-48$ saat süre ile inkübe edilmiştir. İnkübasyondan sonra, inhibisyon zonları $\mathrm{mm}$ olarak ölçülmüştür. Ayrıca DMSO (50 $\mu 1)$ çözücü kontrolü olarak kullanılmıştır. Antimikrobiyal aktivite gösteren bitki ekstraktları daha sonra farklı konsantrasyonlarda bitki eksratı içeren Mueller Hinton Broth ve Sabouraud Dextrose Broth içerisinde MIK (Minimal İnhibisyon Konsantrasyon) değerleri belirlenmiştir (Collins ve ark., 1989). MİK değerleri, gözlemlenebilir büyümeyi/bulanıklığı önleyen tüplerdeki en düşük ekstrakt konsantrasyonu olarak kaydedilmiştir.

\section{BULGULAR ve TARTISMMA}

\section{Yağ asidi kompozisyonuna ait sonuçlar}

Yonuz eriği meyve ekstraktlarının yağ içerikleri Ahırdağı lokasyonundan toplanan örneklerde ortalama olarak \%1,14, Nurhak lokasyonundan toplanan örneklerde ise ortalama olarak \%1,50 olarak bulunmuştur. GC-MS analizi sonucunda elde edilen yağ asidi kompozisyonuna ait veriler Çizelge 1'de ve GC-MS kromatogramları Şekil 2'de verilmiştir. Buna göre, ortalama değerler dikkate alındığında Ahırdağı lokasyonundan toplanan yonuz eriği meyve ekstraktlarının sabit yağının başlica bileşenlerini cis-11,14,17- eikosatrienoik Asit $(\% 31,20)$, oleik asit $(\% 25,41)$, palmitik asit $(\% 14,34)$ ve linoleik asit $(\% 14,12)$ oluşturmaktadır. Nurhak lokasyonundan toplanan yonuz eriği meyve ekstraktlarının sabit yağının başlıca bileşenlerini ise oleik asit $(\% 49,77)$, palmitik asit $(\% 23,05)$ ve linoleik asitin $(\% 5,74)$ oluşturduğu görülmektedir. Analiz sonucuna göre, Ahirdağ 1 lokasyonundan toplanan meyve ekstraktlarında stearik $(\% 4,782)$, alfa ve gama linolenik $(\% 3,58 \mathrm{ve}$ 1,11), cis-8,11,14-eikosatrienoik asit $(\% 1,29)$; Nurhak lokasyonunda ise stearik $(\% 4,89)$ ve behenik $(\% 1,65)$ asitler de miktar bakımından \%1'in üstünde bulunurken diğer yağ asitleri \%1'in altında kalmıştır. Doymuş ve tekli doymamış yağ asitleri bakımından Nurhak lokasyonu; çoklu doymamış yağ asitleri bakımından ise Ahırdağ lokasyonundan toplanan örnek yağlarının daha zengin olduğu görülmüştür.

Literatür taramasında, yonuz eriğinin tohum ya da meyvesinin yağ asidi kompozisyonu konusunda çalışmaya rastlanmamıştır. Matthaeus ve Ozcan (2009), Türkiye'deki farklı çevrelerden topladıkları Prunus cinsine ait 6 türün tohumlarının yağ içeriğgi ve kompoziyonunu araştırdıkları çalışmalarında, 7 farklı yağ asidi tanımlamışlar ve yağ asidi bileşimini bu çalışmadan oldukça farklı bulmuşlardır. Erik tohumlarının oldukça yüksek bir seviyede oleik asit, orta derecede bir miktar linoleik asit ve düşük miktarda doymuş yağ asidi içerdiğini tespit etmişlerdir. Tohum yağlarındaki oleik asit içeriğinin \% 43,9-74,4, linoleik asidin ise $\%$ 9,7-37,0 arasında değiştiğini belirtmişlerdir. $\mathrm{Bu}$ çalışmada da farklı çevrelerden toplanan türlerin meyve ekstraklarındaki major yağ asitlerinden biri oleik asit olurken; diğer yağ asidinin değiştiği görülmektedir. Ahırdağı lokasyonundan toplanan örneklerde major yă asitleri; cis-11,14,17eikosatrienoik $(\% 31,20)$, oleik $(\% 25,41)$, palmitik $(\% 14,34)$ ve linoleik $(\% 14,12)$ asitler iken, Nurhak lokasyonundan toplanan örneklerde oleik $(49,77)$, palmitik $(\% 23,05)$ ve lignoserik $(\% 6,56)$ asitler olmuştur. İki çalışma arasındaki bu yüksek farkın, genetik farklılık ve çalışılan bitki organlarının aynı olmamasından kaynaklandığı düşünülmektedir.

Alfa-linolenik asit oksidasyona duyarlı olduğundan, ısının gerekli olduğu gıda işleme uygulamalarında, bu yağ asidinin miktarı stabilite etmek amaciyla, mümkün olduğu kadar düşük olmalıdır. Öte yandan, tekli ve çoklu doymamış yağ asitlerinin, doymuş yağ asitlerinden daha yüksek içeriğiyle, çalışılan yonuz eriklerinin meyve ekstraktlarından elde edilen yağın yağ asidi bileşimi, insan beslenmesi için oldukça uygundur. Kırıcı ve ark. (2004), gıda için kullanılacak olan yağlarda oleik asitin yüksek; linolenik asit oranının \%3'ün altında; esansiyel bir yağ asidi olan linoleik asit oranının ise mümkün olduğunca yüksek olmasının istendiğini belirtmişlerdir. $\mathrm{Bu}$ özellikler bakımından yonuz 
eriği ekstraktlarına ait yağın istenen özelliklerde olduğu belirlenmiştir.

\section{Toplam fenolik ve flavonoid içerikleri ile antioksidan aktivitesi testlerine ait sonuçlar}

$\mathrm{Bu}$ çalışmada, Folin-Ciocâlteu ve $\mathrm{AlCl}_{3}$ deneyleri kullanılarak yonuz eriği bitkisinin, toplam fenolik ve flavonoid içeriğini karşılaştırmak için farklı ekstraktörler uygulanmış ve sonuçlar Çizelge 2'de verilmiştir. Yapılan analiz sonucunda yonuz eriği meyve ekstraklarındaki fenol miktarının 27,40 ile $62,50 \mathrm{mg}^{\mathrm{GAE} \mathrm{g}^{-1}}$ ve flavonoid miktarının ise 1,38-2,96 $\mathrm{mg} \quad \mathrm{QE} \quad \mathrm{g}^{-1}$ arasında değiştiği görülmüştür. $\mathrm{Bu}$ türün bu değerleri ile ilgili olarak yapılmış olan literatürdeki tek çalıșmada, toplam fenolik içerik $11,35 \mathrm{mg} \mathrm{g}^{-1}$ ve flavonoid içerik ise $0,87 \mathrm{mg} \mathrm{g}^{-1}$ olarak bulunmuştur ki bu değerler, bu çalışmada elde edilen değerlerin altındadır
(Motamed ve Naghibi, 2010). Marinova ve ark. (2005), çeşitli Prunus türlerinin meyve ekstraktlarında toplam fenol ve flavonoid içeriğini araștırdıkları çalışmalarında, Prunus domestica'da sirasiyla 0,30 ve $0,14 \mathrm{mg} \mathrm{g}^{-1} ; P$. persica' da 0,51 ve $0,15 \mathrm{mg} \mathrm{g}^{-1} ; P$. avium'da 0,79 ve $0,20 \mathrm{mg} \mathrm{g}^{-1}$ ve $P$. cerasus vulgaris'te 0,43 ve $0,14 \mathrm{mg} \mathrm{g}^{-1}$ olarak elde etmişlerdir. Cantin ve ark. (2009), $P$. persica'nın 19 farklı kültür bitkisinde yaptıkları çalışmada, toplam fenolik içeriği $0,31-0,45 \mathrm{mg} \mathrm{g}^{-1}$ ve flavonoid içeriği ise $6,90-12,30 \mathrm{mg} \mathrm{g}^{-1}$ arasında bulmuşlardır. Her iki araștırmacının bulguları bu çalışmada elde edilen değerlere göre oldukça düșüktür. Yine $P$. domestica'nın 14 farklı kültür bitkisinin yapraklarının çalıșıldı ı̆ı başka bir çalışmada fenolik içerik $8,08-139,67 \mathrm{mg} \mathrm{g}^{-1}$ ve flavonoid içerik ise $36,60-60,32 \mathrm{mg} \mathrm{g}^{-1}$ olarak elde

Cizelge 1. P. divaricata subsp. divaricata Ledeb. meyve ekstraktlarının yağ asidi kompozisyonları (\%).

Table 1. Fatty acid compositions of fruit extracts of $P$. divaricata subsp. divaricata Ledeb. (\%).

\begin{tabular}{|c|c|c|c|c|}
\hline No. & $\begin{array}{l}\text { Karbon sayıları } \\
\text { Carbon numbers }\end{array}$ & $\begin{array}{l}\text { Yağ asitleri } \\
\text { Fatty acid }\end{array}$ & Ahırdağ 1 & Nurhak \\
\hline 1 & C6:0 & Caproic acid & - & $0,06 \pm 0,02$ \\
\hline 2 & $\mathrm{C} 8: 0$ & Caprylic acid & - & $0,09 \pm 0,00$ \\
\hline 3 & $\mathrm{C} 10: 0$ & Capric acid & - & $0,04 \pm 0,01$ \\
\hline 4 & $\mathrm{C} 14: 0$ & Myristic acid & $0,38 \pm 0,01$ & $0,13 \pm 0,00$ \\
\hline 5 & C16:0 & Palmitic acid & $14,34 \pm 0,03$ & $23,05 \pm 0,05$ \\
\hline 6 & C17:0 & Heptadecanoic acid & - & $0,17 \pm 0,01$ \\
\hline 7 & $\mathrm{C} 18: 0$ & Stearic acid & $4,78 \pm 0,02$ & $4,89 \pm 0,02$ \\
\hline 8 & $\mathrm{C} 20: 0$ & Arachidic acid & $0,28 \pm 0,02$ & $0,23 \pm 0,02$ \\
\hline 9 & C21:0 & Heneicosanoic acid & $0,40 \pm 0,01$ & - \\
\hline 10 & $\mathrm{C} 22: 0$ & Behenic acid & - & $1,65 \pm 0,03$ \\
\hline 11 & $\mathrm{C} 23: 0$ & Tricosanoic acid & $0,51 \pm 0,00$ & $0,32 \pm 0,01$ \\
\hline \multirow[t]{2}{*}{12} & $\mathrm{C} 24: 0$ & Lignoceric acid & $1,14 \pm 0,02$ & $6,56 \pm 0,01$ \\
\hline & & $\begin{array}{l}\text { Doymuş yag asitleri toplamı } \\
\text { Sum of saturated fatty acids }\end{array}$ & 21,83 & 37,18 \\
\hline 13 & C14:1 & Myristoleic acid & - & $0,04 \pm 0,01$ \\
\hline 14 & C16:1 & Palmiteloic acid & $0,53 \pm 0,00$ & $0,77 \pm 0,01$ \\
\hline 15 & $\mathrm{C} 17: 1$ & cis-10-Heptadecanoic acid & $0,40 \pm 0,02$ & $0,18 \pm 0,01$ \\
\hline 16 & C18:1 & Oleic acid & $25,41 \pm 0,03$ & $49,77 \pm 0,02$ \\
\hline \multirow[t]{2}{*}{17} & C24:1 & Nervonic acid & $0,24 \pm 0,03$ & $2,93 \pm 0,03$ \\
\hline & & $\begin{array}{l}\text { Tekli doymamis yag asitleri toplamı } \\
\text { Sum of monounsaturated fatty acids }\end{array}$ & 26,57 & 53,69 \\
\hline 18 & C18:2 & Linoleic acid & $14,12 \pm 0,03$ & $5,74 \pm 0,01$ \\
\hline 19 & $\mathrm{C} 18: 3$ & gama-Linolenic acid & $1,11 \pm 0,01$ & $0,76 \pm 0,01$ \\
\hline 20 & $\mathrm{C} 18: 3$ & alfa-Linolenic acid & $3,58 \pm 0,00$ & $0,48 \pm 0,00$ \\
\hline 21 & C20:3 & cis-8,11,14-Eicosatrienoic acid & $1,29 \pm 0,01$ & $0,25 \pm 0,00$ \\
\hline 22 & $\mathrm{C} 20: 3$ & cis-11,14,17- Eicosatrienoic acid & $31,20 \pm 0,04$ & - \\
\hline 23 & $\mathrm{C} 20: 4$ & Arachidonic acid & - & $0,09 \pm 0,01$ \\
\hline 24 & $\mathrm{C} 22: 2$ & cis-13.16-Docosadienoic acid & $0,31 \pm 0,01$ & - \\
\hline \multirow[t]{3}{*}{25} & $\mathrm{C} 22: 6$ & cis-4,7,10,13,16,19-Docosahexaenoic & - & $1,82 \pm 0,02$ \\
\hline & & $\begin{array}{l}\text { Çoklu doymamis yag asitleri toplam } \\
\text { Sum of polyunsaturated fatty acids }\end{array}$ & 51,61 & 9,14 \\
\hline & & $\begin{array}{l}\text { Toplam } \\
\text { Total }\end{array}$ & 100,00 & 99,99 \\
\hline
\end{tabular}




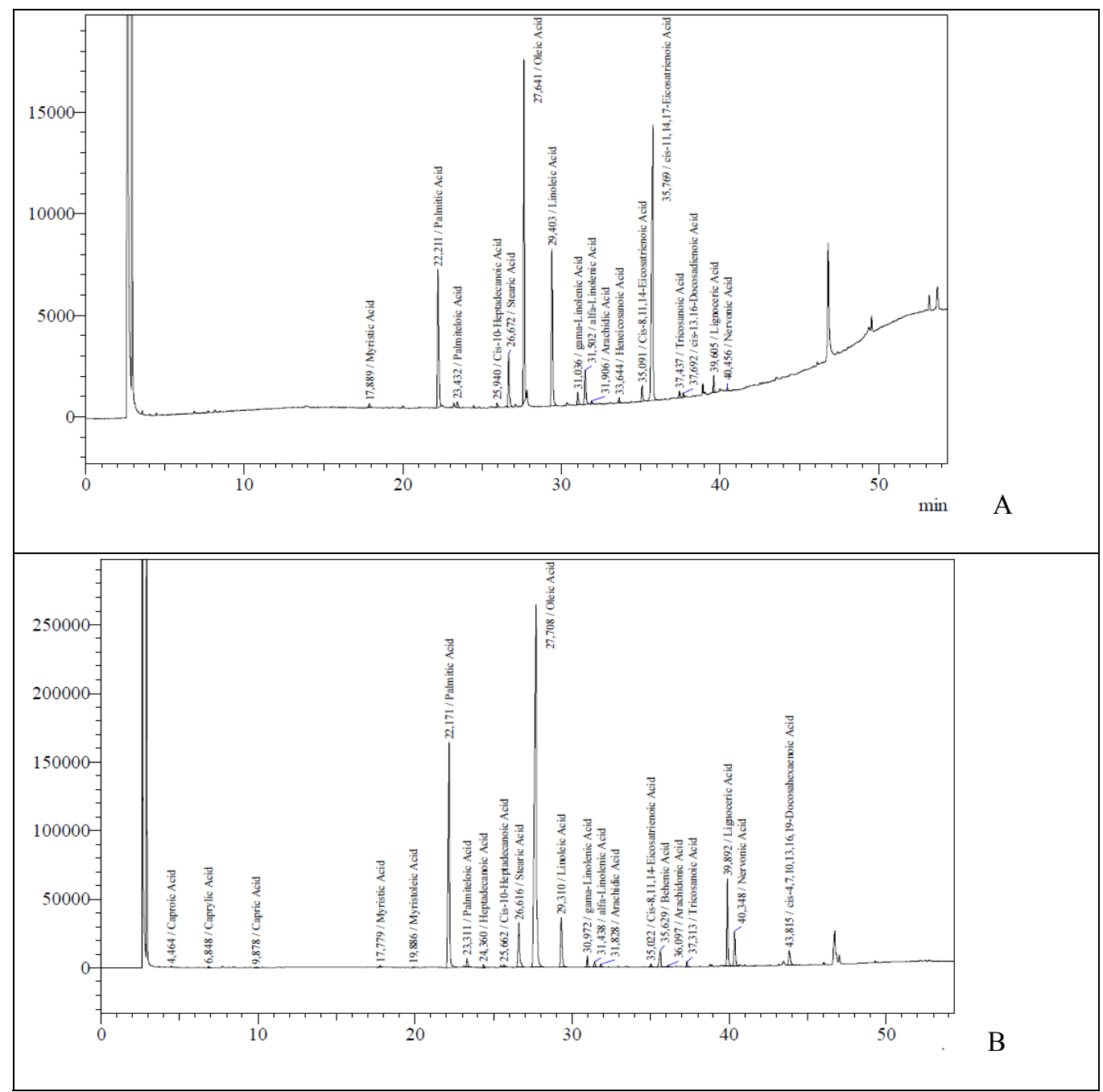

Şekil 2. P. divaricata subsp. divaricata Ledeb. meyve ekstraktlarından elde edilen GC-MS kromatogramları (A: Ahirdağı lokasyonu, B: Nurhak lokasyonu).

Figure 2. GC-MS chromatograms obtained from fruit extracts of $P$. divaricata subsp. divaricata Ledeb. (A: Ahirdağ1 location, B: Nurhak location).

Çizelge 2. P. divaricata subsp. divaricata Ledeb. meyve ekstraktlarının Ahırdağı ve Nurhak lokasyonlarında fenol-flavonoid içerikleri ile antioksidan aktivitesi ortalama ve standart hata değerleri.

Table 2. The mean values and standart errors of antioxidant activity and phenol-flavonoid contents of fruit extracts of $P$. divaricata subsp. divaricata Ledeb. in Ahırdağı and Nurhak locations.

\begin{tabular}{|c|c|c|c|c|}
\hline \multirow[b]{2}{*}{ İçerik / Content } & \multicolumn{2}{|c|}{ Ahırdağ̀ } & \multicolumn{2}{|c|}{ Nurhak } \\
\hline & $\begin{array}{l}\text { Soksalet } \\
\text { Soxhalete }\end{array}$ & USB & $\begin{array}{l}\text { Soksalet } \\
\text { Soxhalete }\end{array}$ & USB \\
\hline Fenol /Phenol (mg GAE g ${ }^{-1}$ ) & $34,90 \pm 0,04$ & $62,50 \pm 0,11$ & $27,40 \pm 0,01$ & $37,40 \pm 0,06$ \\
\hline Flavonoid (mg QE g $\left.{ }^{-1}\right)$ & $1,66 \pm 0,04$ & $2,96 \pm 0,11$ & $1,38 \pm 0,01$ & $1,81 \pm 0,17$ \\
\hline $\mathrm{IC}_{50}$ değeri//C $\mathrm{IC}_{50}$ Value $(\% \mathrm{DPPH})\left(\mathrm{mg} \mathrm{mL}^{-1}\right)$ & $2,15 \pm 0,06$ & $1,47 \pm 0,05$ & $1,96 \pm 0,06$ & $1,75 \pm 0,04$ \\
\hline FRAP $\left(\mu \mathrm{g} \mathrm{AAE} \mathrm{g}^{-1}\right)$ & $19,06 \pm 0,36$ & $31,05 \pm 0,82$ & $16,92 \pm 0,41$ & $20,82 \pm 1,04$ \\
\hline
\end{tabular}

edilmiştir ki, bu değerler de bu çalışmada elde edilen değerlerin üstündedir (Mocan ve ark., 2018). Ballistreri ve ark. (2013), fenolik içerik ile meyvelerin antioksidan aktivitesi arasında güçlü ilişkiler bulunduğunu belirtmiştir. Bu çalışmada da fenolik içeriğin yüksek olduğu uygulamada antioksidan aktivitenin de fazla olduğu görülmüştür. 
DPPH radikal temizleme modeli, çeșitli örneklerin serbest radikalleri temizleme yeteneğini değerlendirmek için yaygın olarak kullanılır. DPPH analizinde IC50 değeri ne kadar düşük olursa, serbest radikallerin o kadar iyi temizlenmesi mümkün olur ve böylece serbest radikal zincir reaksiyonu bozulabilir (Lim ve ark., 2007). Genel olarak, biyoaktif maddelerin antioksidan özellikleri, çeşitli yöntemler kullanılarak araştırılmaktadır. $\mathrm{Bu}$ çalışmada antioksidan aktiviteler DPPH ve FRAP testleri ile belirlenmiş ve sonuçlar Çizelge 2 'de sunulmuştur. IC50 değerinin 1,47-2,15 $\mathrm{mg} \mathrm{mL}^{-1}$ ve FRAP değerinin ise $16,92-31,05 \mu \mathrm{g} \mathrm{AAE}^{-1}$ arasında değiştiği belirlenmiştir. Serteser ve ark. (2009), $P$. divaricata subsp. divaricata'nın meyvelerinin baz1 antioksidan özelliklerini incelendikleri çalışmalarında, IC50 değerini 1,69 bulmuşlardır ki bu değer, bu çalışmada elde edilen değerlerin sinırları içerisindedir. Mocan ve ark. (2018)'nın $P$. domestica'da elde ettiği sonuçlara (IC50 değeri: 1,83-3,50 mg mL $\mathrm{mL}^{-1}$ ) kiyasla daha düşük değerler elde edilmiştir ki bu, indirgeme gücünün daha yüksek olduğu anlamına gelmektedir. Çizelge 2 incelendiğinde, Ahırdağı lokasyonundan toplanan yonuz eriği ekstraktlarından elde edilen fenolflavonoid değerlerinin Nurhak lokasyonundan toplanan örneklerden daha yüksek ve antioksidan aktivite gücünün de daha fazla olduğu görülmektedir. Diğer yandan ekstraktörler karşılaştırıldığında, ultrasonik banyonun soksalete nazaran, yonuz eriği ekstraktlarının biyoaktif profilini ortaya çıkarmada daha etkili olduğu belirlenmiştir. Bitkilerden elde edilen fenolik bileşiklerin ve flavonoidlerin, gıda ürünlerinde bol miktarda antioksidan aktiviteye sahip olduğu gösterilmiştir. Genel olarak, yüksek radikal süpürme aktivitesine sahip ekstraktlar, yüksek bir fenolik içeriğe sahiptir. Hagen ve ark. (2009), bitki örneklerinin antioksidan kapasitesi ile toplam fenol ve flavonoller arasında pozitif bir ilişki olduğunu belirtmişlerdir. $\mathrm{Bu}$ çalışmada da benzer şekilde, toplam fenolik ve flavonoid içeriklerinin yüksek bulunduğu uygulamalarda antioksidan aktivitenin de yüksek olduğu görülmüştür. Ferioli ve ark. (2013)'nın belirttiği gibi, lokaliteler, bireyler, toprak besini, bakım ve iklim farklılıklarının bitkideki biyoaktif maddelerin içeriğini ve miktarını farklı oranlarda etkilemektedir. $\mathrm{Bu}$ çalışmada da lokalite, birey farklılığı bitkilerin kimyasal içeriklerinde farklılığa neden olmuştur.

\section{Antimikrobiyal aktivite testine ait sonuçlar}

Farklı lokasyonlardan toplanan $P$. divaricata subsp. divaricata örneklerinden, farklı metodlar kullanılarak elde edilen ekstraktların antimikrobiyal aktiviteleri değerlendirildiğinde önemli bir farklılık gözlemlenmemiştir (Çizelge 3). Petride yapılan testlere bakıldığında E. faecium tüm Gram pozitif ve Gram negatif bakteriler ile mayalara karşı bir inhibisyon gerçekleştirdiği gözlenmiştir (Çizelge 4). Klinik izolatlar içerisinde en yüksek antimikrobiyal etki Gram negatif organizmalar E.coli ve $K$. pnemonia'a karş1 gözlenirken $C$. albicans ve $C$. parapsilosis en az olmuştur. Bitkisel ekstraktlarda gözlenen antimikrobiyal etkilere; flavonoid, polifenolik bileşikler, taninler ve terpenler gibi çok sayıda fitokimyasal maddenin sebep olduğu bir çok araştırmacı tarafından rapor edilmiştir (Mojab ve ark., 2008). Yapılan analizler de $P$. divaricata subsp. divaricata meyvelerinin yüksek oranlardaki fenol ve flavonoid içeriklerinin antimikrobiyal aktiviteden sorumlu olmaları muhtemeldir.

\section{SONUÇ ve ÖNERILER}

$\mathrm{Bu}$ çalışma, Kahramanmaraş’ta doğal olarak yetişen yabani bir bitki olan yonuz eriği ile ilgili meyvelerinin biyokimyasal özellikleri ve antimikrobiyal aktivitelerinin belirlenmesi kapsamlı olarak yapılmış ilk çalışmadır. Öncelikle iki farklı lokasyondan ve dolayısıyla farklı çevre ve iklim koşullarından toplanan genotipler genetik kaynak olarak herbaryumda muhafaza edilmiştir. Flavonoidler ve fenolik bileşiklerin toplam içeriği konusundaki yapılan bu araştırmada $P$. divaricata subsp. divaricata'nın önemli miktarda flavonoid ve fenolik bileşik içerdiği tespit edilmiştir. $\mathrm{Bu}$ fitokimyasal bileşenlerin bitkilerin antioksidan kapasitesinden sorumlu olduğu bilinmektedir. Hâlihazırda yöre insanının diyetinde yer alan bu değerli bitkinin, yüksek biyoaktif içeriğe ve antioksidan aktiviteye sahip olması nedeniyle sağlık açısından faydaları bu çalışma ile ortaya konulmuştur. Ayrica, besin olarak tüketilen yonuz eriği meyvelerinin insan sağlı̆̆ için faydaları olan ya $\breve{g}$ asitleri bakımından da zengin olduğu belirlenmiştir. 
Çizelge 3. P. divaricata subsp. divaricata Ledeb. meyvelerinin metanol ekstraklarının antimikrobiyal aktiviteleri (inhibisyon zonu çapları ve oyuk agar çapları beraber, $\mathrm{mm}$ ).

Table 3. Antimicrobial activity of methanol extracts of $P$. divaricata subsp. divaricata Ledeb. fruits (inhibition zone diameters and well diameters together, $\mathrm{mm}$ ).

\begin{tabular}{|c|c|c|c|c|c|c|}
\hline \multirow[b]{2}{*}{ Organizma/Organism } & \multicolumn{2}{|c|}{ Ahırdağ1 } & \multicolumn{2}{|c|}{ Nurhak } & \multicolumn{2}{|c|}{$\mathrm{AK}^{* *}$} \\
\hline & $\begin{array}{l}\text { Soksalet } \\
\text { Soxhalete }\end{array}$ & USB & $\begin{array}{c}\text { Soksalet } \\
\text { Soxhalete }\end{array}$ & USB & $\mathrm{Cxm}$ & Nys \\
\hline E.coli* & 15 & 16 & 15 & 16 & - & TE \\
\hline K. pneumonia * & 14 & 14 & 13 & 14 & - & TE \\
\hline B. subtilis ATCC 6633 & 22 & 16 & 22 & 19 & - & $\mathrm{TE}$ \\
\hline $\mathrm{MRSA}^{*}$ & 7 & 8 & - & 8 & - & TE \\
\hline S. aureus ATCC 29213 & 10 & 10 & 10 & 10 & 16 & TE \\
\hline S. lutea ATCC 9341NA & 18 & 18 & 11 & 11 & 25 & TE \\
\hline E. faecalis ATCC 29212 & 14 & 16 & 14 & 14 & 18 & TE \\
\hline E. faecium * & - & - & - & - & 18 & TE \\
\hline C. albicans* & 7 & 8 & 7 & 7 & $\mathrm{TE}^{* * *}$ & 18 \\
\hline C. parapsilosis * & 7 & 7 & 7 & 7 & TE & 18 \\
\hline
\end{tabular}

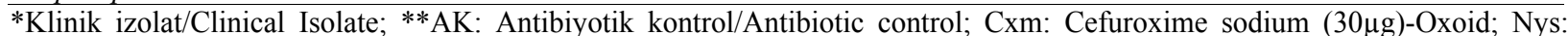
Nystatine 100U; ***TE: Test edilmedi/Not tested.

Çizelge 4. Tüp dilusyon metodu ile $P$. divaricata subsp. divaricata Ledeb. meyvelerinin metanol ekstraklarının MIK (Minimal inhibisyon Konsantrasyon) değerleri ( $\mathrm{mg} / \mathrm{ml})$.

Table 4. MIC (Minimal Inhibition Concentration) values of methanol extracts of $P$. divaricata subsp. divaricata Ledeb. fruits with tube dilution method $(\mathrm{mg} / \mathrm{ml})$.

\begin{tabular}{|c|c|c|c|c|}
\hline \multirow{2}{*}{ Organizma/Organism } & \multicolumn{2}{|c|}{ Ahırdağ 1} & \multicolumn{2}{|c|}{ Nurhak } \\
\hline & $\begin{array}{c}\text { Soksalet } \\
\text { Soxhalete }\end{array}$ & USB & $\begin{array}{c}\text { Soksalet } \\
\text { Soxhalete }\end{array}$ & USB \\
\hline E.coli* & 4 & 2 & 4 & 4 \\
\hline K. pneumonia $*$ & 2 & 2 & 2 & 2 \\
\hline B. subtilis ATCC 6633 & 2 & 2 & 2 & 2 \\
\hline MRSA* & 4 & 4 & 4 & 4 \\
\hline S. aureus ATCC 29213 & 2 & 2 & 2 & 2 \\
\hline S. lutea ATCC $9341 \mathrm{NA}$ & 2 & 1 & 2 & 2 \\
\hline E. faecalis ATCC 29212 & 2 & 2 & 2 & 2 \\
\hline E. faecium * & 4 & 4 & 4 & 4 \\
\hline C. albicans* & 2 & 2 & 8 & 8 \\
\hline C. parapsilosis * & 2 & 2 & 4 & 4 \\
\hline
\end{tabular}

*: Klinik izolat / Clinical isolate.

\section{LITERATÜR LISSTESI}

Anonymous. 1993. Performance Standards for Antimicrobial Disc Suspectibility Tests. Approved Standard. NCCLS Publication M2-A5, Villanova, PA, USA, 1993.

Ballistreri, G., A. Continella, A. Gentile, M. Amenta, S. Fabroni, and P. Rapisarda. 2013. Fruit quality and bioactive compounds relevant to human health of sweet cherry (Prunus avium L.) cultivars grown in Italy. Food Chem. 140 (4): 630-638.

Benzie, I. F., and J. J. Strain. 1996. The ferric reducing ability of plasma (FRAP) as a measure of "antioxidant power": the FRAP assay. Anal Biochem. 239 (1): 7076.
Blackhall, M. L., R. Berry, N. W. Davies, and J. T. Walls. 2018. Optimized extraction of anthocyanins from Reid Fruits' Prunus avium 'Lapins' cherries. Food Chem. 256: 280-285.

Brand-Williams, W., M. E. Cuvelier, and C. L. W. T. Berset. 1995. Use of a free radical method to evaluate antioxidant activity. LWT-Food Sci Technol. 28 (1): 25-30

Cantin, C. M., M. A. Moreno, and Y. Gogorcena. 2009. Evaluation of the antioxidant capacity, phenolic compounds, and vitamin $\mathrm{C}$ content of different peach and nectarine [Prunus persica (L.) Batsch] breeding progenies. J. Agric. Food Chem. 57 (11): 4586-4592. 
Chang, C. C., M. H. Yang, H. M. Wen, and J. C. Chern. 2002. Estimation of total flavonoid content in propolis by two complementary colorimetric methods. J. Food Drug Anal. 10 (3): 178-182.

Collins, C. H., P. M. Lyne, and J. M. Grange. 1989. Collins and Lyne's Microbiological Methods. Sixth Edition, Butterworths Co. Ltd. London.

Davis, P. H. (Ed.) 1965-1985. Flora of Turkey and the East Aegean Islands. Vol. 1-9. Edinburgh: Edinburgh University Press.

Dönmez, A. A., and Ş. Yıldırımlı. 2000. Taxonomy of the genus Prunus L. (Rosaceae) in Turkey. Turkish Journal of Botany 24 (3): 187-202.

Ekor, M. 2014. The growing use of herbal medicines: issues relating to adverse reactions and challenges in monitoring safety. Frontiers in pharmacology 4: 177. https://doi.org/10.3389/fphar.2013.00177.

Faydaoğlu, E. ve M. S. Sürücüoğlu. 2011. Geçmişten günümüze tıbbi ve aromatik bitkilerin kullanılması ve ekonomik önemi. Kastamonu Üniversitesi Orman Fakültesi Dergisi 11 (1): 52-67.

Ferioli, F., E. Giambanelli, L. F. D'Antuono, H. S. Costa, T. G. Albuquerque, A. S. Silva, and B. Koçaoglu. 2013. Comparison of leafy kale populations from Italy, Portugal, and Turkey for their bioactive compound content: phenolics, glucosinolates, carotenoids, and chlorophylls. J. Sci. Food Agric. 93 (14): 3478-3489.

Hagen, S. F., G. I. A. Borge, K. A. Solhaug, and G. B. Bengtsson.2009. Effect of cold storage and harvest date on bioactive compounds in curly kale (Brassica oleracea L. var. acephala). Postharvest Biol Technol. 51 (1): 36-42.

Heleno, S. A., P. Diz, M. A. Prieto, L. Barros, A. Rodrigues, M. F. Barreiro, and I. C. Ferreira. 2016. Optimization of ultrasound-assisted extraction to obtain mycosterols from Agaricus bisporus L. by response surface methodology and comparison with conventional Soxhlet extraction. Food chem. 197: 1054-1063.

Hintz, T., K. K. Matthews, and R. Di. 2015. The use of plant antimicrobial compounds for food preservation. BioMed research international 246264, 1-12.

Kırıcı, S., H. İbrikçi, M. A. Gür, A. Özel, D. Karaaslan, M. Kırpık, C. Akınc1, İ. Gül ve M. İnan. 2004. Güneydoğu Anadolu Bölgesi'nde kolza (Brassica napus L.) çeșitlerinde azot miktarı ve bitki yoğunluğunun tohum verimi ve yağ oranına etkisi. TÜBİTAK TOGTAG TARP Proje No. 1778: 1-54. Proje sonuç Raporu.

Kültür, Ş. 2007. Medicinal plants used in Kırklareli province (Turkey). J. Ethnopharmacol. 111 (2): 341-364.

Lim, Y. Y., T. T. Lim, and J. J. Tee. 2007. Antioxidant properties of several tropical fruits: A comparative study. Food Chem. 103 (3): 1003-1008.
Marinova, D., F. Ribarova, and M. Atanassova. 2005. Total phenolics and total flavonoids in Bulgarian fruits and vegetables. J. Chem. Technol. Metall. 40 (3): 255-260.

Matthaeus, B., and M. M. Ozcan. 2009. Fatty acids and tocopherol contents of some Prunus spp. kernel oils. J Food Lipids 16 (2): 187-199.

Mattioli, R., L. Mosca, A. Sánchez-Lamar, I. Tempera, and R. Hausmann. 2018. Natural bioactive compounds acting against oxidative stress in chronic, degenerative, and infectious diseases. Oxidative medicine and cellular longevity, 3894381, 1-2.

Miliauskas, G., P. R.Venskutonis, and T. A. Van Beek. 2004. Screening of radical scavenging activity of some medicinal and aromatic plant extracts. Food Chem. 85 (2): $231-237$.

Minaiyan, M., A. Ghannadi, A. Movahedian, P. Ramezanlou, and F. S. Osooli. 2014. Effect of the hydroalcoholic extract and juice of Prunus divaricata fruit on blood glucose and serum lipids of normal and streptozotocininduced diabetic rats. Res Pharm Sci. 9 (6): 421.

Mocan, A., A. Diuzheva, S. Carradori, V. Andruch, C. Massafra, C. Moldovan, and G. D. Marconi. 2018. Development of novel techniques to extract phenolic compounds from Romanian cultivars of Prunus domestica L. and their biological properties. Food Chem Toxicol. 119: 189-198.

Mojab, F., M. Poursaeed, H. Mehrgan, and S. Pakdaman. 2008. Antibacterial activity of Thymus daenensis methanolic extract. Pak. J. Pharm. Sci. 21 (10): 210-213.

Motamed, S. M., and F. Naghibi. 2010. Antioxidant activity of some edible plants of the Turkmen Sahra region in northern Iran. Food Chem. 119 (4): 1637-1642.

Obanda, M., P. O. Owuor, and S. J. Taylor. 1997. Flavanol composition and caffeine content of green leaf as quality potential indicators of Kenyan black teas. J. Sci. Food Agric. 74 (2): 209-215.

Ramalhosa, E., T. Delgado, L. Estevinho, and J. Alberto Pereira. 2011. Hazelnut (Corylus avellana L.) cultivars and antimicrobial activity. pp. 627-636. In: V. R. Preedy, R. R. Watson, V. B. Patel (Eds.). Nuts and Seeds in Health and Disease Prevention (1st ed.). London, Burlington, San Diego: Academic Press,

Reales, A., D. J. Sargent, K. R. Tobutt, and D. Rivera. 2010.Phylogenetics of Eurasian plums, Prunus L. section Prunus (Rosaceae), according to coding and non-coding chloroplast DNA sequences. Tree Genetics \& Genomes 6: 37-45.

Rivera-Rangel, L. R., K. I. Aguilera-Campos, A. GarcíaTriana, J. G. Ayala-Soto, D. Chavez-Flores, and L. Hernández-Ochoa. 2018. Comparison of oil content and fatty acids profile of Western Schley, Wichita, and native pecan nuts cultured in Chihuahua, Mexico. Journal of lipids 4781345, 1-6. https://doi. org/10.1155/2018/4781345. 
Schieber, A., F. C. Stintzing, and R. Carle. 2001. By-products of plant food processing as a source of functional compounds-recent developments. Trends Food Sci Technol. 12 (11): 401-413.

Septembre-Malaterre, A., F. Remize, and P. Poucheret. 2018. Fruits and vegetables, as a source of nutritional compounds and phytochemicals: Changes in bioactive compounds during lactic fermentation. Food Res Int. 104: 86-99.

Serteser, A., M. Kargığlu, V. Gök, Y. Bağci, M. M. Özcan, and D. Arslan. 2009. Antioxidant properties of some plants growing wild in Turkey. Grasas y Aceites 60 (2): $147-154$
Teixeira, M., T. Altmayer, F. Bruxel, C. R. Orlandi, N. F. de Moura, C. N. Afonso, and E. M. de Freitas. 2019. Rubus sellowii Cham. and Schlitdl. (Rosaceae) fruit nutritional potential characterization. Brazilian Journal of Biology 79 (3): 510-515.

Wöhrmann, T., D. Guicking, K. Khoshbakht, and K. Weising. 2011. Genetic variability in wild populations of Prunus divaricata Ledeb. in northern Iran evaluated by EST-SSR and genomic SSR marker analysis. Genet Resour Crop Evol. 58 (8): 1157-1167. 